\title{
Evaluation of national trends in the utilization of partial nephrectomy in relation to the publication of the American Urologic Association guidelines for the management of clinical T1 renal masses
}

\author{
Michael A Liss ${ }^{1}$, Song Wang ${ }^{1}$, Kerrin Palazzi ${ }^{1}$, Ramzi Jabaji ${ }^{1}$, Nishant Patel ${ }^{1}$, Hak J Lee ${ }^{1}$, J Kellogg Parsons ${ }^{1}$
} and Ithaar $\mathrm{H}$ Derweesh ${ }^{1,2^{*}}$

\begin{abstract}
Background: Partial nephrectomy has been underutilized in the United States. We investigated national trends in partial nephrectomy (PN) utilization before and after publication of the American Urological Association (AUA) Practice Guideline for management of the clinical T1 renal mass.

Methods: We identified adult patients who underwent radical (RN) or PN from November 2007 to October 2011 in the Nationwide Inpatient Sample (NIS). PN prevalence was calculated prior to (11/2007-10/2009) and after Guidelines publication (11/2009-10/2011) and compared the rate of change by linear regression. We also examined the nephrectomy trends in patients with chronic kidney disease (CKD). Statistical analysis included linear regression to determine point-prevalence of PN rates in CKD patients and logistic regression to identify variables associated with PN.

Results: During the study period, 30,944 patients underwent PN and 64,767 RN. The prevalence PN increased from $28.9 \%$ in the years prior to guideline release to $35.3 \%$ in the years following guideline release with an adjusted odds ratio (OR) of $1.24(\mathrm{Cl} 1.01-1.54 ; \mathrm{p}=0.049)$. The rate of PN significantly increased throughout the study period $\left(R^{2} 0.15, p=0.006\right)$ : however, the rate of change was not increased after the guidelines. $(p=0.46)$. Overall rate of $P N$ in patients with CKD did not increase over time $\left(R^{2} 0.0007, p=0.99\right)$.

Conclusion: We noted a 6.4\% absolute increase in PN after release of the AUA guidelines on clinical T1 renal mass was published; however, the rate of increase was not likely associated with guideline release. The rate of PN performed is increasing; however, further investigation regarding medical decision-making surrounding PN is needed.
\end{abstract}

Keywords: Kidney cancer, Outcomes, Nephrectomy

\section{Background}

Radical nephrectomy (RN) had been the standard of care for renal malignancy for nearly 4 decades [1]. However, increasing detection of small renal masses (SRM) has lead to a stage migration of renal masses $[2,3]$. Smaller tumors suggest the opportunity perform more nephron

\footnotetext{
* Correspondence: iderweesh@gmail.com
'Department of Urology, University of California San Diego Health System, La

* Correspondence: iderweesh@gmail.com
'Department of Urology, University of California San Diego Health System, La Jolla, CA, USA

2UCSD Moores Cancer Center, 3855 Health Sciences Drive, La Jolla, CA 92093, MC 0987, USA
}

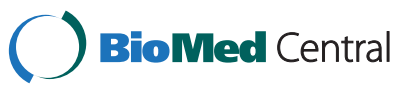

(c) 2014 Liss et al.; licensee BioMed Central. This is an Open Access article distributed under the terms of the Creative Commons Attribution License (http://creativecommons.org/licenses/by/4.0), which permits unrestricted use, distribution, and reproduction in any medium, provided the original work is properly credited. The Creative Commons Public Domain Dedication waiver (http://creativecommons.org/publicdomain/zero/1.0/) applies to the data made available in this article unless otherwise stated.

sparing surgery; however, large national databases have suggested underutilization of PN [4-7].

Increased knowledge of chronic cardiac and metabolic sequelae of $\mathrm{RN}$, along with data suggesting oncologic equivalence for partial (PN) compared to radical nephrectomy for SRM, has prompted reconsideration of surgical approaches to renal masses [8-14]. In 2009, the American Urological Association (AUA) published evidence-based practices guidelines for the management of clinical T1a renal masses as a guide for clinicians to consider PN to be the reference standard for T1a renal 
masses, and emphasizing the importance of renal preservation in patients with chronic kidney disease (CKD) [15].

To investigate the potential shorter-term impact of publication of the AUA T1 Renal Mass Guidelines, we analyzed the overall and rate of utilization of $\mathrm{PN}$ versus radical nephrectomy $(\mathrm{RN})$ in a national cohort before and after the AUA Guideline release, with a focused analysis of utilization trends of $\mathrm{PN}$ in patients with nondialysis dependent CKD.

\section{Methods}

\section{Study design}

As the primary outcome, we investigated the proportion and rate of PN performed after the release of the AUA T1 Renal Mass Guidelines compared to prior using a publicly available cross-sectional inpatient database (National Inpatient Sample, NIS). Patients were divided into two groups consisting of a 2-year span prior to and 2 year after the release of the AUA T1 Renal Mass Guidelines. A secondary outcome is to investigate the rates of RN vs. PN in patients with non-dialysis dependent chronic kidney disease (CKD) [ICD 9 code for CKD stages 3-4; i.e. glomerular filtration rate (GFR) of $59-31$ and $30-15 \mathrm{ml} / \mathrm{min} /$ $1.73 \mathrm{~m}^{2}$, respectively)] in both time periods. Additionally, we investigated patient and external factors associated with performance of RN vs. PN in order to identify potential changes in disparities regarding utilization of nephron sparing surgery and the possible factors associated with patient selection.

\section{Database cohort: the nationwide inpatient sample}

We analyzed data from November 2009 to October 2011 in the Nationwide Inpatient Sample (NIS), which is part of the Healthcare Cost and Utilization Project (HCUP) sponsored by the Agency for Healthcare Research and Quality (AHRQ). The database is de-identified and publically available; therefore, is exempt from formal IRB review. It is the largest all-payer inpatient care database that is publicly available in the United States, containing data from 5 to 8 million hospital stays per year. In 2010, data included 1,056 hospitals located in 42 states, making up a $20 \%$ stratified sample of U.S. hospitals [12]. Inpatient stay records include clinical and resource use information available from discharge abstracts. Weighted sampling allows estimates for national trends. The data is publically available and de-identified so no patient consent was needed for this study. The NIS is available for purchase at http://www.hcup-us.ahrq.gov/nisoverview.jsp.

\section{Variables}

We focused on age, Charlson comorbidity index, and CKD as specific variables, which are emphasized in with the AUA clinical T1 Renal Mass Guidelines. However, CKD coding in the NIS can be non-specific for stage depending on how the medical history was coded. Therefore, we will use the CKD codes for a general term CKD with subsequent sub analysis of specifically CKD stage 3 and 4 (eGFR range of 15-59). Other abstracted exposure variables included race, gender, treatment year, income by zip code, geographic region of treatment (Northeast, South, Midwest, and West), hospital renal surgery volume, insurance type, the hospital size, hospital location (rural vs. urban), and hospital type (teaching versus non-teaching).

\section{Case selection \\ General}

We identified all hospital admissions in patients older than 18 years with a primary or secondary procedure code for PN (PN) (55.4) or radical nephrectomy (RN) (55.5, 55.51, 55.52 and 55.54) from November 2007 to October 2011.

\section{Oncologic extent}

The NIS does not contain tumor size or disease specific staging. Additionally, patients with locally advanced, locoregional or metastatic disease are more likely to undergo RN. Therefore, we excluded patients undergoing concomitant surgeries suggestive of advanced disease, including splenectomy $(41.4,41.42,41.43)$, liver resection $(50.2,50.21-26,50.29,50.3)$, pancreas resection $(52.5,52.51-53,52.59,52.6,52.7)$, bowel or colon resection $(45.5,45.50-52,45.61-62,45.7,45.71,45.73-76$, $45.79,45.8,45.81-83)$, or thrombectomy with vascular reconstruction $(37.10,38.05,38.07,38.45,38.47,38.65$, $38.67,38.75$, 38.77, 38.87, 39.6, 39.61, 39.63, 39.66) to reduce the potential for bias by burden of disease.

\section{Other kidney surgery}

The ICD-9 procedure code for nephrectomy does not distinguish between radical and simple operations. Consequently, we excluded all patients with a concomitant ICD9 diagnosis code for kidney donor (V59.4), and infectious etiologies including acute and chronic pyelonephritis (590.0, 590.00, 590.01, 590.1, 590.10 and 590.11) and renal/ perinephric abscess (590.2) since these diagnoses might represent the indication for performing the procedure. We also excluded those patients with a diagnosis of renal pelvic or ureteral tumor (189.1 or 189.2) since nephrectomy and nephroureterectomy utilize the same ICD-9 procedure code. We also excluded autosomal dominant polycystic kidney disease $(753.12,753.13,753.14)$ since the diagnosis might affect pre-operative renal function as well as surgical indication and selection.

\section{Comorbidity and chronic kidney disease}

Co-morbid conditions assessed include hypertension (Dx CCS 98, 99), diabetes (Dx CCS 49, 50) and obesity (ICD-9 278.0, 278.01, 278.00). A subgroup analysis of 
patients with a discharge ICD-9 diagnosis of chronic renal insufficiency (585x) was performed. We divided patients with a specified CKD stage into those with end stage renal failure (ESRF) requiring dialysis (CKD stage 5, ICD-9 585.5). CKD 6 is an unspecified diagnosis code of 585.6; however, most patients fell into this category possibly due to coding indiscretion to CKD stage.

\section{Statistical analysis}

The 20\% NIS sample was weighted to estimate all national inpatient stays and used for all calculations. The primary outcome of proportion of $\mathrm{PN}$ performed 2 years before (November 2007-October 2011) and 2 years following (November 2009-October 2011) publication of Guideline for management of the clinical T1 renal mass (AUA Renal Mass Guideline) was examined by the Chi Squared test. The secondary outcome was change in rates of $\mathrm{PN}$ over the two time periods were calculated using the total number of inpatients in each year creating simple linear regression models to approximate the change in procedure incidence over time (months). The proportion of PN performed was calculated by the number of partials performed divided by the total number of nephrectomies (RN plus PN). Each time period will have a regression statistical value then the slopes are compared using interactions between the regression lines.

Demographics, clinical and hospital characteristics were compared between groups using chi-squared (Rao \& Scott second order correction), ANOVA, and Student $t$ tests (using Bonferroni correction for inter-group comparisons). We grouped patients based on RN vs. PN as well as pre vs. post AUA T1 Renal Mass Guidelines recommendation to examine demographic differences. Because renal mass treatment may be influenced by age we included age as a continues variable as well as a binary variable at age 60 as this was the median age of partial nephrectomy in the AUA guidelines [15]. Additionally, racial differences are compared due to recent evidence that race and gender may influence surgical decision making [16,17].

Subsequently, we performed multivariable analysis using binary logistic regression models to examine the influence of age, race, sex, co-morbid disease and hospital characteristics on surgery selection; only variables that reached statistical significance in the multivariate model were ultimately included in the final models. SVY coding in STATA v 11.1 (StataCorp, College Station, TX) was used to account for NIS sampling methodology, and probability of type I error was defined a priori as $\alpha=0.05$.

\section{Results}

\section{Population characteristics for partial nephrectomy pre} and post guidelines

We identified 95,711, patients undergoing either PN or Radical Nephrectomy (RN) in the United States from
November 2009 to October 2011. We compared 30,944 patients who received a $\mathrm{PN}$ to 64,767 who received a $\mathrm{RN}$ (Table 1). A significantly higher proportion of PN was performed after 2 years after AUA Renal Mass Guideline publication compared to two years prior guidelines were published than prior (35.3\% vs. 29\%; p < 0.0001). Patients with CKD who underwent PN was not significantly increased post-guidelines compared to pre-guideline $(7.3 \%$ vs. 7.9\%; $p=0.2997)$. More specifically, 26.3\% (626/2376) PN were performed prior to guideline publication with Stage III/Stage IV CKD compared 28.2\% (970/3439) to post-Guideline publication which corresponds to a nonsignificant increase $(\mathrm{p}=0.126)$.

Regarding ethnicity/racial demographics, increased PN were noted in Caucasian, African-American, Hispanic, and Asian patients from $28.9 \%, 28.4 \%, 25.1 \%, 26.1 \%$ before the guidelines and $35.6 \%, 33.3 \%, 32.7 \%$, and $32.3 \%$ after Guideline publication, respectively $(\mathrm{p}<0.001)$. The largest improvement was $7.6 \%$ occurring in the Hispanic population. Proportionally, more PN were performed in patients with diabetes $(20.8 \%$ vs. $23.3 \% ; \mathrm{p}=0.005)$ and obesity $(12.8 \%$ vs. $15.1 \%$; $\mathrm{p}=0.011)$. Less PN were performed at hospitals that performed less than 25 renal surgeries per year $(82.6 \%$ vs. $62.2 \%$; $<<0.0001)$. Despite the improvement length of stay in the hospital (3.1 days vs. 2.7 days; $\mathrm{p}<0.001)$, the expense of $\mathrm{PN}$ increased by $\$ 3,158$ (USD; $\mathrm{p}<0.0001$ ).

\section{Population characteristics for partial nephrectomy vs. radical nephrectomy}

We identified many discrepancies between the demographics of patients who received a $\mathrm{RN}$ compared to a PN (Table 2). Non-modifiable factors for radical nephrectomy patients would include age and multiple comorbidities (both $\mathrm{p}<0.001$ ). We show social factors may play role in surgical preference because hospital location, hospital volume, and patient wealth (insurance and zip code) were all highly significant factors in our study.

\section{Multivariate analysis of pre and post AUA T1 renal mass guidelines publication}

Using logistic regression analysis, patients had a $24 \%$ increased odds of having a PN after Guideline publication (OR 1.242 95\%CI 1.001-1.542; $\mathrm{p}=0.0489$ ) More PN were performed on obese patients (OR 1.527 95\%CI 1.1132.058; $\mathrm{p}=0.0054)$. Lastly, patients who had surgery at a hospital that does at least 25 nephrectomies (partial or radical) had a 2 -fold higher odds of having a $\mathrm{PN}$ after Guideline publication than prior $(\mathrm{p}<0.0001)$

\section{Trends of partial nephrectomies in relation to guideline release}

The overall proportion of PN performed from increased significantly throughout the study period $\left(R^{2}=0.24 ; p=0.0005\right.$; 
Table 1 Patient demographics of partial nephrectomy before and after the publication of the T1a renal AUA guidelines recommendations

\begin{tabular}{|c|c|c|c|}
\hline \multirow[t]{3}{*}{ Demographic } & \multirow{2}{*}{$\begin{array}{l}\text { Before Guidelines } \\
N=27357 \text { (PN) }\end{array}$} & \multirow{2}{*}{$\begin{array}{l}\text { After Guidelines } \\
\mathrm{N}=34336 \text { (PN) }\end{array}$} & \multirow[t]{3}{*}{$p$-value } \\
\hline & & & \\
\hline & $\mathrm{N}=94457(\mathrm{PN}+\mathrm{RN})$ & $\mathrm{N}=97314(\mathrm{PN}+\mathrm{RN})$ & \\
\hline Mean Age \pm SE & $58.2 \pm 0.2$ & $58.4 \pm 0.2$ & 0.3888 \\
\hline Age Group & & & 0.3325 \\
\hline$<60$ & $14024(51.3) / 44364$ & $17228(50.2) / 45978$ & \\
\hline$\geq 60$ & 13333(48.7) /50093 & 17108(49.8)/51336 & \\
\hline Gender & & & 0.1857 \\
\hline Male & $15558(57.1) / 53780$ & 20015(58.4)/56715 & \\
\hline Female & $11672(42.9) / 40344$ & $14245(41.6) / 40406$ & \\
\hline Race & & & $<0.0001$ \\
\hline Caucasian & $16714(61.1) / 57803$ & $23530(68.5) / 66065$ & \\
\hline African-American & $2059(7.5) / 7244$ & 3190(9.3)/9575 & \\
\hline Hispanic & $1540(5.6) / 6125$ & 2489(7.3) /7609 & \\
\hline Asian & $440(1.6) / 1681$ & $567(1.7) / 1752$ & \\
\hline Other & $6604(24.1) / 21604$ & $4558(13.3) 12313$ & \\
\hline Income (Zip Code) & & & 0.8705 \\
\hline$<\$ 50,000$ & $12000(45.1) / 44943$ & $15053(44.7) / 46743$ & \\
\hline$\geq \$ 50,000$ & 14609(54.9) /47486 & 18634(55.3) /48732 & \\
\hline Hypertension & 15427(43.6) /56001 & 20009(58.3)/59732 & 0.0842 \\
\hline Diabetes & $5702(20.8) / 20288$ & $7998(23.3) / 23219$ & 0.0056 \\
\hline Obesity & $3493(12.8) / 10846$ & $5180(15.1) / 13513$ & 0.0114 \\
\hline Chronic Kidney Disease & $1986(7.3) / 12058$ & $2697(7.9) / 13685$ & 0.2997 \\
\hline CKD Stages & & & 0.6560 \\
\hline Stage1 & $10(0.5) / 25$ & $30(1.1) / 75$ & 0.2353 \\
\hline Stage2 & $83(4.2) / 353$ & 124(4.6) /439 & 0.5822 \\
\hline Stage3 & $480(24.2) / 1770$ & $766(28.4) / 2620$ & 0.1144 \\
\hline Stage4 & $146(7.3) / 606$ & 204(7.6) /819 & 0.6660 \\
\hline Stage5/ESRD & $15(0.8) / 182$ & $24(0.9) / 163$ & 0.7484 \\
\hline Stage unspecified & $1252(63.0) / 9121$ & $1548(57.4) / 9568$ & 0.9392 \\
\hline Charlson Comorbidity Index & & & 0.3327 \\
\hline 0 & $16780(61.3) / 52204$ & 20528(59.8)/53063 & \\
\hline 1 & $6763(24.7) / 21901$ & $8965(26.1) / 23394$ & \\
\hline 2 & 1948(7.1) /7365 & 2375(6.9) /7594 & \\
\hline $3+$ & $1866(6.8) / 12988$ & $2468(7.2) / 13262$ & \\
\hline Insurance & & & 0.8561 \\
\hline Private & $15224(55.8) / 45206$ & 18797(54.9) /45917 & \\
\hline Medicare & $9018(33.0) / 37728$ & $11416(33.3) / 38316$ & \\
\hline Medicaid & $1561(5.7) / 5794$ & 2014(5.9) /6464 & \\
\hline Other & $1500(5.5) / 5565$ & 2031(5.9) /6352 & \\
\hline Hospital Bed Number & & & 0.3397 \\
\hline Small & 2350(8.8) /8298 & $3077(9.2) / 8808$ & \\
\hline Medium & $5742(21.5) / 20598$ & $5766(17.2) / 18948$ & \\
\hline Large & 18569(69.6) /63430 & 24696(73.6) /67702 & \\
\hline
\end{tabular}




\begin{tabular}{|c|c|c|c|}
\hline Hospital Nephrectomy Volume/year & & & $<0.0001$ \\
\hline$<25$ & 737(82.6) /4159 & $824(62.2) / 4065$ & \\
\hline $25-49$ & $88(9.9) / 417$ & 273(20.6) /886 & \\
\hline $50-99$ & $43(4.8) / 189$ & 140(10.6) /418 & \\
\hline $100+$ & $24(2.7) / 73$ & $88(6.6) / 190$ & \\
\hline Hospital Location & & & 0.4592 \\
\hline Rural & $1128(4.2) / 5236$ & 1205(3.6) /5467 & \\
\hline Urban & 25534(95.8) /87089 & 32334(96.4) /89992 & \\
\hline Hospital Region & & & 0.8938 \\
\hline Northeast & $6041(22.6) / 17794$ & $8283(24.5) / 19444$ & \\
\hline Midwest & $7309(27.3) / 24490$ & $9413(27.9) / 26002$ & \\
\hline South & $7699(28.8) / 29451$ & $9983(29.6) / 31888$ & \\
\hline West & $5692(21.3) / 20876$ & $6104(18.1) / 18747$ & \\
\hline Teaching & & & 0.4759 \\
\hline Non-teaching & $6482(24.3) / 31172$ & $8920(26.6) / 31383$ & \\
\hline Teaching & 20180(75.7) /61153 & 24619(73.4) /64075 & \\
\hline Median Length of Stay (IQR), days & $3.1(2.1-4.4)$ & $2.7(1.7-3.9)$ & $<0.0001$ \\
\hline Median Total Charges for Stay (IQR), \$ & $35223(24931-49394)$ & $38381(27440-55923)$ & $<0.0001$ \\
\hline Died during hospitalization & $45(0.2) / 703$ & $50(0.1) / 774$ & 0.8318 \\
\hline
\end{tabular}

Figure 1). We divided this trend into two separate linear regression lines to determine the rate of change of PN performed prior to Guideline publication $\left(R^{2}=0.40 \mathrm{p}=0.0007\right)$ and after Guideline publication $\left(R^{2}=0.30 \mathrm{p}=0.0041\right)$. We then compared the interaction between the regression lines noting they were not statistically different $(\mathrm{p}=0.4613)$. Figure 1 displays the trends over time. There was no increase in PN for patient with CKD over this time period $\left(R^{2} 0.0007, p=0.8592\right)$ or between the two time periods ( $R 20.02$ vs. $0.04 ; \mathrm{p}=0.2425$ ). Linear regression could not be performed on specifically CKD stage III/IV due to low sample size leading to potentially large error.

\section{Discussion}

We noted a $6.4 \%$ absolute increase in the proportion of $\mathrm{PN}$ in a two-year period performed before and after the guideline release; however, PN remains only about $35 \%$ of all nephrectomies performed. We used an adjusted multivariable analysis to identify a $23 \%$ increased odds of having a $\mathrm{PN}$ in the 2 years after Guidelines publication (Table 3). We were expecting to identify a rise in the rate of PN after Guideline publication, however there was no difference in incidence (Figure 1). While increase in PN utilization increase after AUA T1 Renal Mass guidelines publication was recently reported by Bjurlin et al. who noted a one year increase in PN proportion from $27 \%$ to $32 \%$ [18], our data are longer term and the conclusions we draw while seemingly similar (i.e., an overall increase). Nonetheless our results demonstrate that increase in PN utilization was more likely due to the overall steady rise in incidence over time rather than the AUA T1 Renal Mass Guidelines making a significant immediate impact (Figure 1). We describe increases in PN for high risk patients such as those with obesity, diabetes, and hypertension. Unfortunately, we noted no change in PN proportion with preoperative non-dialysis dependent CKD before and after the AUA T1 Renal Mass Guideline publication (Figure 2). While we are unable to target specific reasoning behind the lack of increase in partial nephrectomy among non-dialysis depended CKD patients, such as tumor factors, this finding is concerning considering it is highlighted as an imperative indication of $\mathrm{PN}$ in the Guidelines [15]. Moreover, the AUA guideline is similar to the EAU guidelines regarding treatment of renal mass with preference toward nephron sparing surgery (initially published in June, 2007 with update in 2010) [19,20]. We highlight this finding as a potential quality of care issue which deserves further follow up.

Patients presenting with a renal mass and concurrent CKD are at highest risk of renal related morbidity and mortality [21-23]. However, our study shows the United States continues to struggle to provide PN to patients because of social issues such as the patient's financial means and where they reside, which agrees with reports 
Table 2 Patient demographics comparing partial nephrectomy and radical nephrectomy over the 4 year study period

\begin{tabular}{|c|c|c|c|}
\hline \multirow[t]{2}{*}{ Demographics } & \multirow{2}{*}{$\begin{array}{l}\text { Partial Nephrectomy } \\
N=61693\end{array}$} & \multirow{2}{*}{$\begin{array}{l}\text { Radical Nephrectomy } \\
N=130078\end{array}$} & \multirow[t]{2}{*}{$p$-value } \\
\hline & & & \\
\hline Mean Age \pm SE & $58.3 \pm 0.2$ & $60.3 \pm 0.2$ & $<0.0001$ \\
\hline Age Group & & & $<0.0001$ \\
\hline$<60$ & $31251(50.7)$ & $59090(45.4)$ & \\
\hline$\geq 60$ & $30441(49.3)$ & $70988(54.6)$ & \\
\hline Gender & & & 0.8440 \\
\hline Male & $35572(57.9)$ & $74922(57.7)$ & \\
\hline Female & $25917(42.1)$ & $54832(42.3$ & \\
\hline Race & & & 0.6064 \\
\hline Caucasian & $40245(65.2)$ & $83623(64.3)$ & \\
\hline African-American & $5249(8.5)$ & 11570(8.9) & \\
\hline Hispanic & $4029(6.5)$ & $9705(7.5)$ & \\
\hline Asian & 1007(1.6) & 2425(1.9) & \\
\hline Other & $11162(18.1)$ & $22755(17.5)$ & \\
\hline Income (Zip Code) & & & $<0.0001$ \\
\hline$<\$ 50,000$ & 27052(44.9) & 64633(50.6) & \\
\hline$\geq \$ 50,000$ & $33242(55.1)$ & $62976(49.4)$ & \\
\hline Hypertension & $35436(57.4)$ & $80297(61.7)$ & $<0.0001$ \\
\hline Diabetes & $13701(22.2)$ & 29806(22.9) & 0.1767 \\
\hline Obesity & $8673(14.1)$ & $15687(12.1)$ & $<0.0001$ \\
\hline Chronic Kidney Disease & $4683(7.6)$ & $21060(16.2)$ & $<0.0001$ \\
\hline CKD Stages & & & $<0.0001$ \\
\hline Stage 1 & $40(0.9)$ & $60(0.3)$ & 0.6139 \\
\hline Stage 2 & $206(4.4)$ & $586(2.8)$ & 0.0421 \\
\hline Stage 3 & $1246(26.6)$ & $3144(14.9)$ & 0.0004 \\
\hline Stage 4 & $350(7.5)$ & 1075(5.1) & 0.0009 \\
\hline Stage 5 / ESRD & $40(0.8)$ & $306(1.5)$ & $<0.0001$ \\
\hline Stage unspecified & $2800(59.8)$ & 15890(75.4) & $<0.0001$ \\
\hline Charlson Comorbidity Index & & & $<0.0001$ \\
\hline 0 & $37308(60.5)$ & $67959(52.2)$ & \\
\hline 1 & $15728(25.5)$ & $29566(22.7)$ & \\
\hline 2 & $4323(7.0)$ & $10636(8.2)$ & \\
\hline $3+$ & 4334(7.0) & 21916(16.8) & \\
\hline Insurance & & & $<0.0001$ \\
\hline Private & $34022(55.3)$ & $57101(44.0)$ & \\
\hline Medicare & 20435(33.2) & $55609(42.8)$ & \\
\hline Medicaid & $3575(5.8)$ & $8684(6.7)$ & \\
\hline Other & $3531(5.7)$ & $8387(6.5)$ & \\
\hline Hospital Bed Number & & & 0.1792 \\
\hline Small & $5428(9.0)$ & 11678(9.2) & \\
\hline Medium & $11508(19.1)$ & $28038(22.0)$ & \\
\hline Large & 43265(71.9) & $87867(68.8)$ & \\
\hline Hospital Nx Volume/year & & & $<0.0001$ \\
\hline$<25$ & $1560(70.4)$ & $6663(81.5)$ & \\
\hline
\end{tabular}


Table 2 Patient demographics comparing partial nephrectomy and radical nephrectomy over the 4 year study period (Continued)

\begin{tabular}{|c|c|c|c|}
\hline $25-49$ & $361(16.3)$ & $942(11.5)$ & \\
\hline $50-99$ & 184(8.3) & $424(5.2)$ & \\
\hline $100+$ & 112(5.1) & $150(1.8)$ & \\
\hline Hospital Location & & & $<0.0001$ \\
\hline Rural & 2333(3.9) & $8371(6.6)$ & \\
\hline Urban & $57868(96.1)$ & $119212(93.4)$ & \\
\hline Hospital Region & & & 0.0009 \\
\hline Northeast & 14324(23.7) & 22913(17.9) & \\
\hline Midwest & 16723(27.6) & $33770(26.3)$ & \\
\hline South & $17683(29.2)$ & $43656(34.1)$ & \\
\hline West & $11795(19.5)$ & $27828(21.7)$ & \\
\hline Teaching & & & $<0.0001$ \\
\hline Non-teaching & $15401(25.6)$ & $47154(37.0)$ & \\
\hline Teaching & $44800(74.4)$ & $82429(63.0)$ & \\
\hline Median Length of Stay (IQR), days & $2.9(1.9-4.2)$ & $3.4(2.2-5.2)$ & $<0.0001$ \\
\hline Median Total Charges for Stay (IQR), \$ & $36832(26298-53058)$ & $37359(25669-59124)$ & $<0.001$ \\
\hline Died during hospitalization & $93(0.2)$ & 1384(1.1) & $<0.0001$ \\
\hline
\end{tabular}

from other reports from the NIS [24] and SEER Medicare data [24]. Recent health reform in American healthcare may change these trends and should be followed over time [25]. Despite current changes in healthcare, issues such as access to care, appropriate training, and hospital resources are also concerns for urologists. For example, urologists were criticized for poor adherence to guideline recommendations regarding a lower than anticipated use of intravesical chemotherapy for nonmuscle invasive bladder cancer in population studies [26]. However when thoroughly investigated to improve care, the investigators found that the initial the baseline

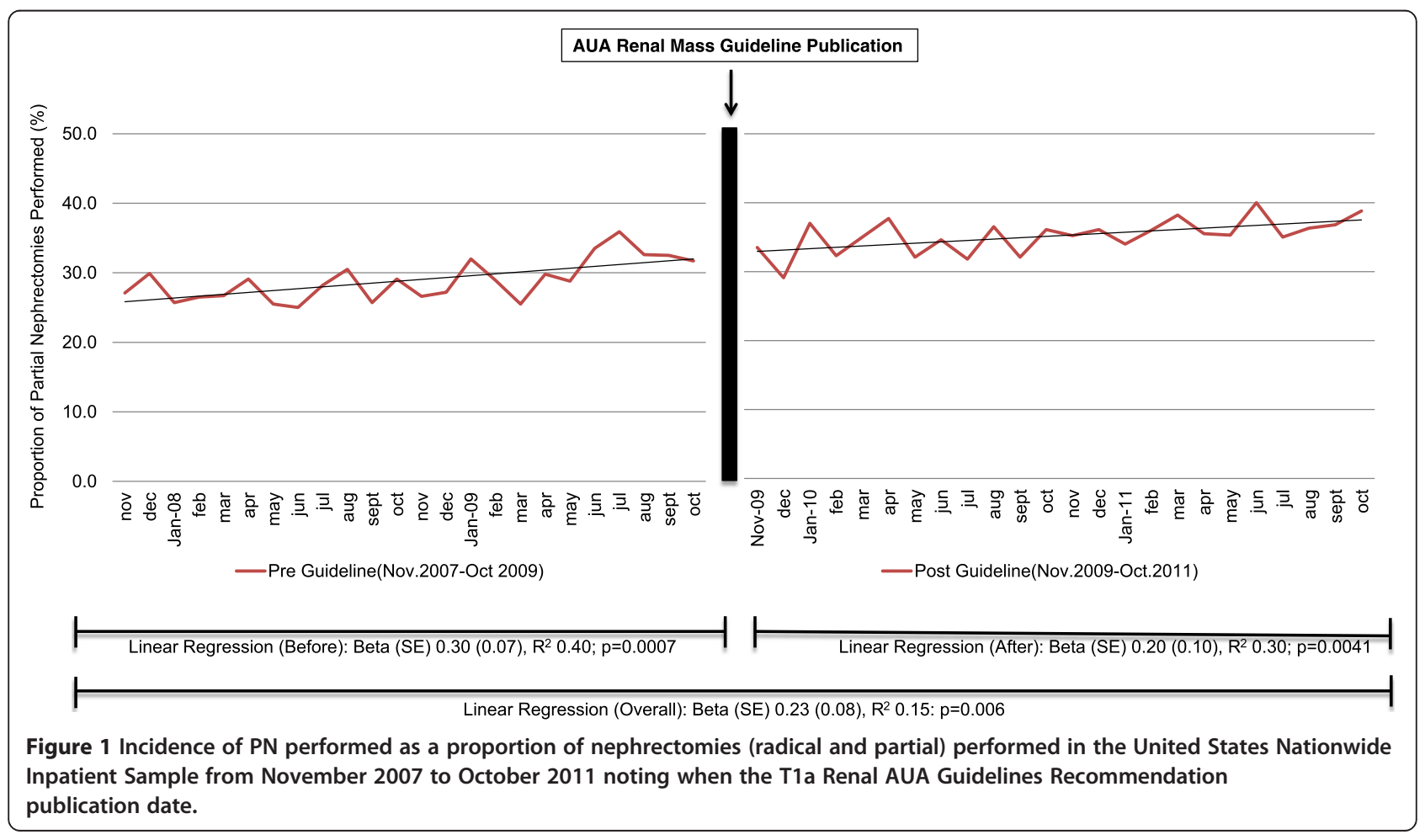


Table 3 Multivariable analysis comparing partial nephrectomy vs. radial nephrectomy using the 2 year study period prior to publications of the T1a renal AUA guidelines recommendations as reference Before AUA T1 Renal Guideline (reference) vs. After AUA T1 Renal Guideline

\begin{tabular}{|c|c|c|c|c|}
\hline & Odds Ratio & 95\% Wald Confidence Limits & $\mathbf{P}$ & Overall $\mathrm{P}$ \\
\hline Partial Nephrectomy vs. Radical Nephrectomy (reference) & 1.242 & $1.001-1.542$ & 0.0489 & \multirow{6}{*}{$<0.0001$} \\
\hline Obesity Yes vs. No (reference) & 1.527 & $1.133-2.058$ & 0.0054 & \\
\hline \multicolumn{4}{|l|}{ Nephrectomy Hospital Volume Less than 25 cases (reference) } & \\
\hline Volume $25-49$ cases & 2.09 & $1.600-2.731$ & \multirow{3}{*}{$<0.0001$} & \\
\hline Volume $50-99$ cases & 2.222 & $1.535-3.217$ & & \\
\hline Volume $100+$ cases & 2.566 & $1.430-4.605$ & & \\
\hline
\end{tabular}

rates of non-adherence where actually justified [27]. The true reasons for not performing a $\mathrm{PN}$ also need to be studied in a similar fashion to the studies regarding nonmuscle invasive bladder cancer, potentially a utilization of the newly developed American Urologic Association Quality Registry (AQUA).

Another potential reason for lack of increased adoption of $\mathrm{PN}$ for $\mathrm{T} 1$ renal neoplasms is that the seemingly overwhelming and robust retrospective data supporting PN has been called into question by publication of only prospective randomized randomized trial to address this topic, EORTC 30904, which was published in April 2011. This trial randomized 541 patients [PN $(n=268) /$ RN ( $n=273)$ ], with a median follow-up of 9.3 years, and noted that overall survival with a hazard ratio (HR) of 1.50 , testing for non-inferiority was not significant $(\mathrm{p}=$
$0.77)$, and test for superiority was significant $(\mathrm{p}=0.03)$ in favor for RN, though in RCC patients there were no significant differences with respect to overall survival. These findings were presented cautiously given shortcomings in study design and execution [13], however, they have already generated a great deal of controversy amongst thought leaders [18,22,23]. For the observation period and our analysis however, the impact of this study and its findings are likely limited and not noted. Indeed, longer observation is requisite to evaluate the impact of this study both on practice patterns in the United States, as well as in the formulation of updates to the AUA Guidelines document.

The criticism for PN utilization of only $35 \%$ in this population based cohort is tempered by the overall rise in incidence of PN in the past 4 years as well as the lack

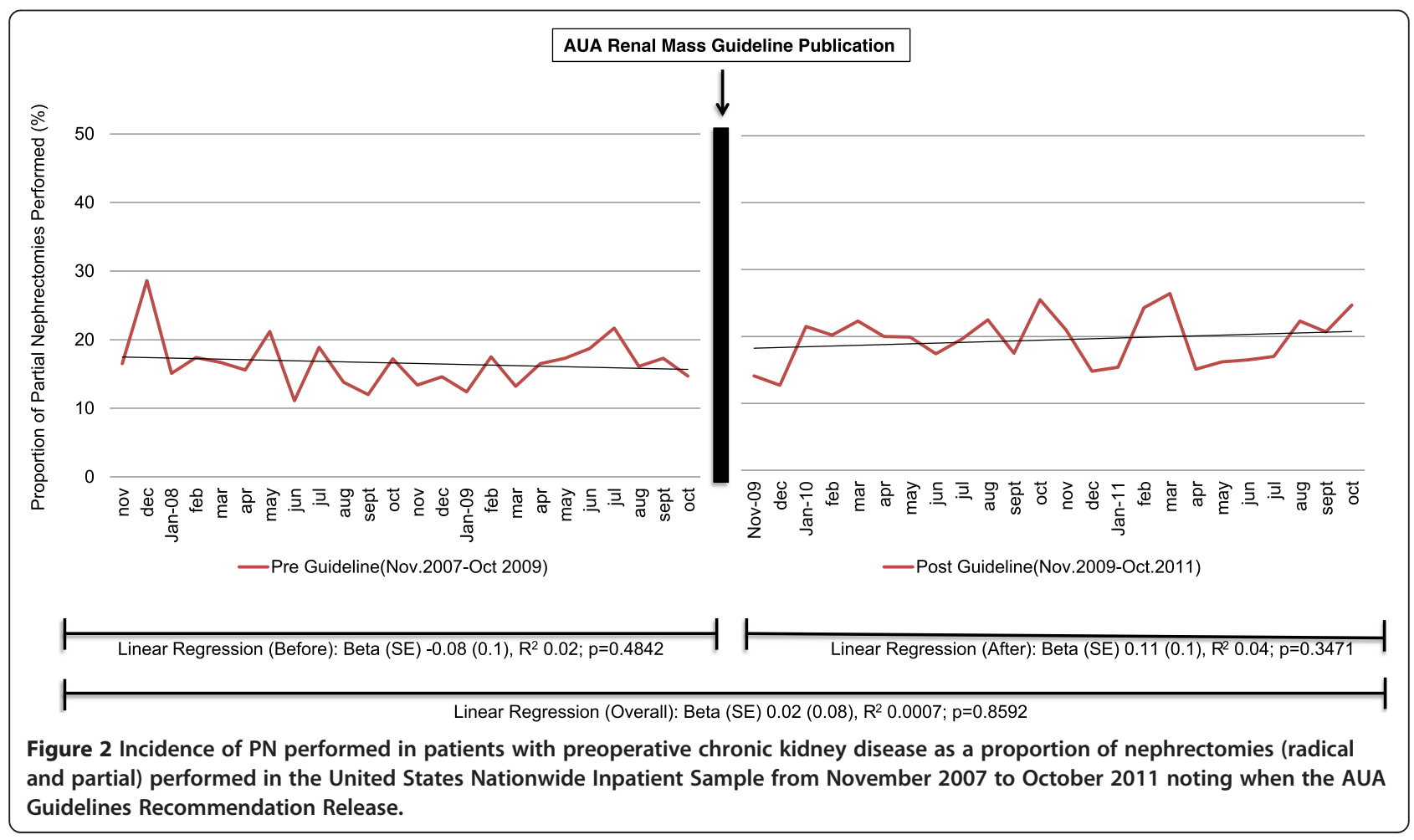


of evidence investigating physician clinical decisionmaking. We identified the largest improvement in PN performed based on hospital volume. In multivariable analysis, patients had a 2 fold increased odds chance of having a $\mathrm{PN}$ if the hospital performs at least 25 renal cases (partial or radical nephrectomies) per year confirming results of prior studies using the NIS [28]. Various reasons may account for this increase. Some reasons for the change in volume may include lower volume hospitals increasing number of PN performed, reflection of current referral patterns, and a combination of both. Additionally, PN in obese patients increased as which most likely is reflecting the increasing obesity epidemic in the United States, which is likely a welcome development given the fact that obesity is a driver for CKD as well [29].

We performed this study not to determine causality of the AUA T1 Renal Mass Guidelines on PN in the United States, but to identify potential opportunities for improvement. Creation of a guideline should only be the beginning of a continuous process of improvement as the ultimate success of depends on critical evaluation over time [30]. In general, guidelines are data driven documents that provide assistance to physicians and come after a majority of the physicians have already adopted the practice [31]. PN has been performed for more than a century, yet continued debate remains regarding its benefit and utilization [13,32,33]. The adoption of PN may be due in part to changes in technology such as laparoscopy and robotic surgery [4,7]. Indeed our findings that the median hospital length of stay has decreased while there may be a rise in overall cost of procedure for $\mathrm{PN}$, while likely indicative increasing adoption of minimally invasive partial nephrectomy (laparoscopic or robotic) our group has reported in previous studies [34,35].

Limitations in the data derived from national databases are only as accurate as the codes that have been chosen for the patient. The NIS database does not have pathologic data and therefore may not solely focus on cT1a renal cortical masses. However, the NIS was chosen for its strength in the documentation of the procedure itself as well as the fact that up to $25 \%$ of small renal masses have benign histology, and would therefore not be documented in oncology driven databases [15]. Moreover, the pathology of the renal mass is usually not available to the surgeon prior to the decision for type of surgery, and we sought to examine trends in procedure utilization as opposed to oncologic outcomes. Though only 4 years are evaluated in our analysis, it is possible that tumor stage may have changed over time and could confound the analysis. We have provided extensive exclusion criteria to remove patients with advanced tumors from our analysis, which have been validated by our group and others in previous analyses
$[6,20,24]$. Furthermore, CKD can be a generalized term and we did note variation within the CKD stages 2-5 codes. Nonetheless, the rate of CKD in patients undergoing $\mathrm{RN}$ or $\mathrm{PN}$ was $4.4 \%$ overall, which is similar in rate to the $4.3 \%$ prevalence of CKD Stage 1-4 reported in medicare patients and suggests that there is no coding bias favoring reporting of dialysis dependent CKD over CKD Stages 1-4. More specific and accurate determination and documentation of CKD are needed for patients presenting for PN for appropriate counseling.

Partial nephrectomy utilization has increased over the 4 years selected for evaluation and should be recognized. However, the lingering question is how many present with amenable tumors and/or various indications for partial nephrectomy and do not have the option offered. One such patient's are those with CKD, in which a surgical decision could have significant impact on future health in which the urologists is not likely to serve the penalty. Therefore, a concerted effort should be placed on identifying patients who would most benefit from partial nephrectomy and providing that service despite demographic challenges. Additionally, further investigation regarding current clinical decision may provide more immediate problem solving opportunities.

\section{Conclusions}

We have identified a steady increase in PN over the four-year study period and more PN performed after the publication of the AUA Clinical T1 Renal Mass Treatment Guidelines. However, the rate of PN performed after the guidelines release was not faster indicating that other factors may be influencing the adoption of PN. Additional studies and longer-term follow up are needed to determine the practical effects and clinical significance of evidence-based guidelines.

\section{Competing interests}

Dr. Derweesh is a consultant for GlaxoSmithKline, all other authors declare that they have no competing interests.

\section{Authors' contributions}

MAL, Concept generation, study design, obtaining data, statistical analysis and review, manuscript generation, manuscript review. SW, Statistical analysis, manuscript review. KP, Statistical analysis, manuscript review. RJ Data cleaning, Statistical review, manuscript review. NP, Data cleaning, obtaining data, Statistical analysis, manuscript review. HJK, Study design supervision, review of outcomes, data check, manuscript review. JKP, Supervision, Manuscript Revision. IHD, Study design, Initial discussion of outcomes, Statistical review, Critical review, Supervision, Manuscript Revision, Financial Support. All authors reviewed the manuscript and agree with submission for publication.

Acknowledgements

This manuscript was funded by the Steven Weissman Kidney Cancer Research Fund.

Received: 2 August 2014 Accepted: 10 November 2014 Published: 17 December 2014 
References

1. Robson CJ, Churchill BM, Anderson W: The results of radical nephrectomy for renal cell carcinoma. J Urol 1969, 101(3):297-301.

2. Chow WH, Devesa SS, Warren JL, Fraumeni JF Jr: Rising incidence of renal cell cancer in the United States. JAMA 1999, 281(17):1628-1631.

3. Kane CJ, Mallin K, Ritchey J, Cooperberg MR, Carroll PR: Renal cell cancer stage migration: analysis of the national cancer data base. Cancer 2008, 113(1):78-83.

4. Hollenbeck BK, Taub DA, Miller DC, Dunn RL, Wei JT: National utilization trends of partial nephrectomy for renal cell carcinoma: a case of underutilization? Urology 2006, 67(2):254-259.

5. Colli J, Sartor O, Grossman L, Lee BR: Underutilization of partial nephrectomy for stage $\mathrm{t} 1$ renal cell carcinoma in the United States, trends from 2000 to 2008. A long way to go. Clin Genitourin Cancer 2012, 10(4):219-224

6. Cooperberg MR, Mallin K, Kane CJ, Carroll PR: Treatment trends for stage I renal cell carcinoma. J Urol 2011, 186(2):394-399.

7. Tanagho YS, Figenshau RS, Sandhu GS, Bhayani SB: Is there a financial disincentive to perform partial nephrectomy? J Urol 2012, 187(6):1995-1999.

8. Bagrodia A, Darwish OM, Rapoport Y, Margulis V: Risk prediction in the management of small renal masses. Curr Opin Urol 2012, 22(5):347-352.

9. Malcolm JB, Bagrodia A, Derweesh IH, Mehrazin R, Diblasio CJ, Wake RW, Wan JY, Patterson AL: Comparison of rates and risk factors for developing chronic renal insufficiency, proteinuria and metabolic acidosis after radical or partial nephrectomy. BJU Int 2009, 104(4):476-481.

10. Weight CJ, Larson BT, Gao T, Campbell SC, Lane BR, Kaouk JH, Gill IS, Klein $E A$, Fergany AF: Elective partial nephrectomy in patients with clinical $\mathrm{T} 1 \mathrm{~b}$ renal tumors is associated with improved overall survival. Urology 2010, 76(3):631-637.

11. Weight CJ, Lieser G, Larson BT, Gao T, Lane BR, Campbell SC, Gill IS, Novick $A C$, Fergany AF: Partial nephrectomy is associated with improved overall survival compared to radical nephrectomy in patients with unanticipated benign renal tumours. Eur Urol 2010, 58(2):293-298.

12. Woldrich J, Mehrazin R, Bazzi WM, Bagrodia A, Kopp RP, Malcolm JB, Kane CJ, Patterson AL, Wan JY, Derweesh IH: Comparison of rates and risk factors for development of anaemia and erythropoiesis-stimulating agent utilization after radical or partial nephrectomy. BJU Int 2012 109(7):1019-1025.

13. Van Poppel H, Da Pozzo L, Albrecht W, Matveev V, Bono A, Borkowski A, Marechal JM, Klotz L, Skinner E, Keane T, Claessens I, Sylvester R: A prospective randomized EORTC intergroup phase 3 study comparing the complications of elective nephron-sparing surgery and radical nephrectomy for low-stage renal cell carcinoma. Eur Urol 2007, 51(6):1606-1615.

14. MacLennan S, Imamura M, Lapitan MC, Omar MI, Lam TB, HilvanoCabungcal AM, Royle P, Stewart F, MacLennan G, MacLennan SJ, Canfield SE, McClinton S, Leyshon Griffiths TR, Ljungberg B, N'Dow J: Systematic review of oncological outcomes following surgical management of localised renal cancer. Eur Urol 2012, 61(5):972-993.

15. Campbell SC, Novick AC, Belldegrun A, Blute ML, Chow GK, Derweesh $\|_{\text {, }}$ Faraday MM, Kaouk JH, Leveillee RJ, Matin SF, Russo P, Uzzo RG: Guideline for management of the clinical T1 renal mass. J Urol 2009, 182(4):1271-1279.

16. Kates M, Whalen MJ, Badalato GM, McKiernan JM: The effect of race and gender on the surgical management of the small renal mass. Urol Oncol 2013, 31(8):1794-1799.

17. Patel HD, Kates M, Pierorazio PM, Allaf ME: Race and sex disparities in the treatment of older patients with T1a renal cell carcinoma: a comorbiditycontrolled competing-risks model. Urol Oncol 2014, 32(5):576-583.

18. Bjurlin MA, Walter D, Taksler GB, Huang WC, Wysock JS, Sivarajan G, Loeb S, Taneja SS, Makarov DV: National trends in the utilization of partial nephrectomy before and after the establishment of AUA guidelines for the management of renal masses. Urology 2013, 82(6):1283-1289.

19. Ljungberg B, Cowan NC, Hanbury DC, Hora M, Kuczyk MA, Merseburger AS, Patard JJ, Mulders PF, Sinescu IC, European Association of Urology Guideline G: EAU guidelines on renal cell carcinoma: the 2010 update. Eur Urol 2010, 58(3):398-406.

20. Ljungberg B, Hanbury DC, Kuczyk MA, Merseburger AS, Mulders PF, Patard $\mathrm{J}$, Sinescu IC, European Association of Urology Guideline Group for renal cell c: Renal cell carcinoma guideline. Eur Urol 2007, 51(6):1502-1510.

21. Go AS, Chertow GM, Fan D, McCulloch CE, Hsu CY: Chronic kidney disease and the risks of death, cardiovascular events, and hospitalization. N Engl J Med 2004, 351(13):1296-1305.

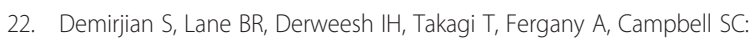
Chronic kidney disease due to surgical removal of nephrons: relative rates of progression and survival. J Urol 2014, 192(4):1057-1063.

23. Smaldone MC, Egleston B, Uzzo RG, Kutikov A: Does partial nephrectomy result in a durable overall survival benefit in the Medicare population? J Urol 2012, 188(6):2089-2094.

24. Becker A, Roghmann F, Trinh QD, Hansen J, Tian Z, Shariat SF, Noldus J, Perrotte P, Graefen M, Karakiewicz PI, Sun M: Sociodemographic disparities in the treatment of small renal masses. BJU Int 2013, 111(8):E274-E282.

25. Rosenbaum L, Shrank WH: Taking our medicine-improving adherence in the accountability era. N Engl J Med 2013, 369(8):694-695.

26. Chamie K, Saigal CS, Lai J, Hanley JM, Setodji CM, Konety BR, Litwin MS, Urologic Diseases in America P: Compliance with guidelines for patients with bladder cancer: variation in the delivery of care. Cancer 2011, 117(23):5392-5401

27. Barocas DA, Liu A, Burks FN, Suh RS, Schuster TG, Bradford T, Moylan DA, Knapp PM, Murtagh DS, Morris D, Dunn RL, Montie JE, Miller DC: Practice based collaboration to improve the use of immediate intravesical therapy after resection of nonmuscle invasive bladder cancer. J Urol 2013, 190(6):2011-2016.

28. Sun M, Bianchi M, Trinh QD, Abdollah F, Schmitges J, Jeldres C, Shariat SF Graefen M, Montorsi F, Perrotte P, Karakiewicz PI: Hospital volume is a determinant of postoperative complications, blood transfusion and length of stay after radical or partial nephrectomy. J Urol 2012, 187(2):405-410.

29. Hedley AA, Ogden CL, Johnson CL, Carroll MD, Curtin LR, Flegal KM: Prevalence of overweight and obesity among US children, adolescents, and adults, 1999-2002. JAMA 2004, 291(23):2847-2850.

30. Basinski AS: Evaluation of clinical practice guidelines. CMAJ 1995, 153(11):1575-1581.

31. Dahm P, Yeung LL, Gallucci M, Simone G, Schunemann HJ: How to use a clinical practice guideline. J Urol 2009, 181(2):472-479.

32. Novick AC, Derweesh I: Open partial nephrectomy for renal tumours: current status. BJU Int 2005, 95(Suppl 2):35-40.

33. Tan HJ, Norton EC, Ye Z, Hafez KS, Gore JL, Miller DC: Long-term survival following partial vs radical nephrectomy among older patients with early-stage kidney cancer. JAMA 2012, 307(15):1629-1635.

34. Parsons JK, Palazzi K, Chang D, Stroup SP: Patient safety and the diffusion of surgical innovations: a national analysis of laparoscopic partial nephrectomy. Surg Endosc 2013, 27(5):1674-1680.

35. Woldrich JM, Palazzi K, Stroup SP, Sur RL, Parson JK, Chang D, Derweesh $\mid H$ Trends in the surgical management of localized renal masses: thermal ablation, partial and radical nephrectomy in the USA, 1998-2008. BJU Int 2013, 111(8):1261-1268.

doi:10.1186/1471-2490-14-101

Cite this article as: Liss et al.: Evaluation of national trends in the utilization of partial nephrectomy in relation to the publication of the American Urologic Association guidelines for the management of clinical T1 renal masses. BMC Urology 2014 14:101.

\section{Submit your next manuscript to BioMed Central and take full advantage of:}

- Convenient online submission

- Thorough peer review

- No space constraints or color figure charges

- Immediate publication on acceptance

- Inclusion in PubMed, CAS, Scopus and Google Scholar

- Research which is freely available for redistribution 